\title{
Specific Alkali Cation Effects in the Transition from Micelles to Vesicles through Salt Addition
}

\author{
A. Renoncourt, ${ }^{\dagger}$ N. Vlachy, ${ }^{\dagger}$ P. Bauduin,${ }^{\dagger}$ M. Drechsler,${ }^{\dagger}$ D. Touraud,${ }^{\dagger}$ J.-M. Verbavatz,${ }^{\S}$ \\ M. Dubois, ${ }^{\prime}$ W. Kunz, ${ }^{* \dagger}$ and B. W. Ninham ${ }^{\perp}$ \\ Institute of Physical and Theoretical Chemistry, University of Regensburg, D-93040 Regensburg, Germany, \\ Institute of Macromolecular Chemistry, University of Bayreuth, D-95440 Bayreuth, Germany, DBCM/ \\ SBCe, C. E. de Saclay, F-91191 Gif sur Yvette Cedex, France, SCM, C. E. de Saclay, F-91191 Gif sur \\ Yvette Cedex, France, and Department of Applied Mathematics, A. N. U. Canberra, Australia
}

Received September 27, 2006. In Final Form: December 3, 2006

\begin{abstract}
The transition of ionic micelles to vesicles with added salts is explored in this paper. The catanionic surfactant solution was comprised of sodium dodecylsulfate (SDS) and dodecyltrimethylammonium bromide (DTAB) with an excess of SDS. The micellar size increased with concentration for all salts. No anion specificity was found, probably because of the excess of SDS. However, when the cation of the added salt was varied, large differences were observed in the hydrodynamic radii of the aggregates. A classification of the cations according to their ability to increase the measured hydrodynamic radii follows a Hofmeister series. The change in aggregate size can be explained by modified counterion binding and dehydration of the surfactant headgroups.
\end{abstract}

\section{Introduction}

It has been known for a long time that double chain surfactants can spontaneously form vesicles. ${ }^{1}$ A similar phenomenon can be observed with mixtures of cationic and anionic surfactants (here called catanionics). These systems display a wide variety of phase behavior and structure. ${ }^{2}$ Spontaneously formed catanionic vesicles are of some interest since they can be tailored at will by varying the anionic/cationic surfactant ratio, the size of the chain length, or the nature of the polar heads. ${ }^{3}$

For dilute systems, local aggregate curvature determined by geometrical constraints embodied in a surfactant packing parameter $P=v /\left(l_{\max } a\right)$-where $v$ and $l_{\max }$ are the volume and length of the hydrophobic part, respectively, and $a$ is the area per molecule at the interface (headgroup) - is a convenient variable that characterizes phase diagrams. ${ }^{4}$ A necessary condition for the formation of vesicles from either single or mixed surfactants can be shown to be that the packing parameter is $1 / 2<P<1$. For a single surfactant, that condition can be satisfied by choosing a double chained surfactant (e.g., didodecyldimethylammonium bromide (DDAB)); for mixed surfactant systems, a pseudo-double chain surfactant is obtained by ion-pair formation between an anionic and a cationic surfactant. 5,6

However, this condition is not sufficient. While the type of aggregate that forms with ionic surfactants can be broadly

* To whom correspondence should be addressed. Fax: (+) 49941943

45 32. E-mail: Werner.Kunz@chemie.uni-regensburg.de.

$\dagger$ University of Regensburg.

$\doteqdot$ University of Bayreuth.

$\S \mathrm{DBCM} / \mathrm{SBCe}$.

"SCM.

$\perp$ A. N. U. Canberra.

(1) Brady, J. E.; Evans, D. F.; Kachar, R.; Ninham, B. W. J. Am. Chem. Soc. 1984, 106, 4279.

(2) Kaler, E. W.; Murthy, A. K.; Rodriguez, B. E.; Zasadzinski, J. A. Science 1989, 245, 1371

(3) Yatcilla, M. T.; Herrington, K. L.; Brasher, L. L.; Kaler, E. W.; Chiruvolu, S.; Zasadzinski, J. A. J. Phys. Chem. 1996, 100, 5874.

(4) Israelachvili, J. N.; Mitchell, D. J.; Ninham, B. W. J. Chem. Soc., Faraday Trans. 2 1976, 72, 1525.

(5) Ninham, B. W.; Evans, D. F. Faraday Discuss. Chem. Soc. 1986, 81, 1.

(6) Marques, E. F.; Regev, O.; Khan, A.; Lindman, B. Adv. Colloid Interface Sci. 2003, 100, 83, and refs therein. understood in terms of a balance between forces due to the packing properties of surfactant tails and those due to double layer electrostatic interactions, conditions for the formation of single or few walled vesicles are very subtle. ${ }^{7-9}$ For effects of global packing constraints and interaggregate interactions, see ref 10.

As the surfactant parameter (intrinsic local curvature) varies in the range $1 / 2<P<1$ by, for example, varying headgroup area via salt addition or temperature or mixing chain lengths, then, if the surfactant chains are flexible, the system forms vesicles that grow as $P$ increases to form a lamellar phase at $P=1$.

If the chains are not flexible, the system at first forms multiwalled vesicles, then vesicles, then lamellar phases again. At $P=1$, this curious phenomenon is due to packing constraints that emerge because the interior and exterior surfactants of a curved bilayer experience very different constraints. Depending on those chain and headgroup constraints, the system can and does form cubic phases at $P \approx 1$. These are phases of zero average curvature but varying Gaussian curvature. Again, with increases in surfactant concentration equivalent to increased repulsion between aggregates, the system can form equilibrium states of supra aggregation. In these, the interior can be micelles or cubic phases protected by few walled vesicles.

The appearance of so many different structures has been known for a very long time ${ }^{11-19}$ but, apart from the system of double 601 .

(7) Mitchell, D. J.; Ninham, B. W. J. Chem Soc., Faraday Trans. 2 1981, 77

(8) André, P.; Filankembo, A.; Lisiecki, I.; Petit, C.; Gulik-Krzywicki, T.; Ninham, B. W.; Pileni, M. P. Adv. Mater. 2000, 12, 119.

(9) Hyde, S. T.; Andersson, S.; Larsson, K.; Blum, Z.; Landh, T.; Lidin, S.; Ninham, B. W. The Language of Shape; Elsevier: Amsterdam, 1997.

(10) André, P.; Ninham, B. W.; Pileni, M. P. New J. Chem. 2001, 25, 563

(11) Ninham, B. W.; Talmon, Y.; Evans, D. F. Science 1983, 221, 1047.

(12) Ninham, B. W.; Evans, D. F.; Wei, G. J. J. Phys. Chem. 1983, 87, 5020.

(13) Ninham, B. W.; Hashimoto, S.; Thomas, J. K. J. Colloid Interface Sci. 1983, $95,594$.

(14) Ninham, B. W.; Evans, D. F. Faraday Discuss. Chem. Soc. 1986, 81, 1 (15) Miller, D.; Bellare, J.; Evans, D. F.; Talmon, Y.; Ninham, B. W. J. Phys. Chem. 1987, 91, 674.

(16) Parker, J. L.; Christenson, H. K.; Ninham, B. W. J. Phys. Chem. 1988, 92,4155 .

(17) Radlinska, E. Z.; Ninham, B. W.; Dalbiez, J. P.; Zemb, T. N. J. Colloid Surf. 1990, 46, 213.

(18) Radlinska, E. Z.; Zemb, T. N.; Dalbiez, J. P.; Ninham, B. W. Lamgmuir $1993,9,2844$. 
chained didodecyldimethylammonium salts with different counterions studied by Ninham and Evans, have been little explored.

The catanionic mixtures provide an excellent vehicle to vary surfactant parameters and to access these subtleties. Supra aggregation as defined previously and cubic phase aggregates are clearly of much interest as model biological systems.

The catanionic vesicles are easy to prepare. There is an expectation that they might also be used as vehicles for controlled delivery of drugs $\mathrm{s}^{20-22}$ or as templates for the synthesis of hollow particles. ${ }^{22-24}$ One advantage of catanionic vesicles as compared with more robust genuinely double chained surfactants is their greater sensitivity to parameters such as temperature ${ }^{25}$ or the presence of salts ${ }^{26}$ used to induce transitions from vesicles to micelles or to precipitation. Of particular interest is the direct transition from micelles to vesicles. Such a phenomenon offers, in principle, an easy way of encapsulating active agents by dissolving them in the micellar phase prior to vesicle formation. Micelle-to-vesicle transitions were already observed when diluting a micellar solution with water, $3,27,28$ changing the anionic/cationic surfactant ratio, ${ }^{29-31}$ increasing the temperature, ${ }^{32}$ or upon the addition of organic additives ${ }^{33}$ and salt. ${ }^{34-36}$ However, as is common in the micellar literature, there has been little awareness or focus on specific ion (Hofmeister) effects. ${ }^{7,37-40}$

The effect of ionic strength on catanionic systems was previously studied experimentally by Brasher et al. ${ }^{26}$ using only one salt. Their results show that the addition of monovalent salt changes the phase behavior and aggregate properties of mixed surfactant solutions. Theoretically, the effect of salt on the catanionics was described by Yuet et al.;7 however, due to the constrictions of the model (smeared surface charges and pointsized ions), they could not reveal the specificity of different ions. To our knowledge, no systematic study of specific salt interactions has been performed in this context. The influence of added salts was previously studied only on the two-phase regions of catanionic systems. ${ }^{36}$ It was shown that for aqueous two-phase systems of non-equimolar surfactant mixtures, the salt effect is mainly dependent on the oppositely charged counterion.

(19) André, P.; Ninham, B. W.; Pileni, M. P. Adv. Colloid Interface Sci. 2001 $89,155$. 163.

(20) Fischer, A.; Hebrant, M.; Tondre, C. J. Colloid Interface Sci. 2002, 248 ,

(21) Tondre, C.; Caillet, C. Adv. Colloid Interface Sci. 2001, 93, 115

(22) Bramer, T.; Paulsson, M.; Edwards, K.; Edsman, K. Pharm. Res. 2003, 20,1661 .

(23) Hentze, H. P.; Raghavan, S. R.; McKelvey, C. A.; Kaler, E. W. Langmuir 2003, 19, 1069

(24) Kepczynski, M.; Ganachaud, F.; Hemery, P. Adv. Mater. 2004, 16, 1861

(25) Amante, J. C.; Scamehorn, J. F.; Harwell, J. F. J. Colloid Interface Sci.

1991, 144, 243

(26) Brasher, L. L.; Herrington, K. L.; Kaler, E. W. Langmuir 1995, 11, 4267.

(27) Renoncourt, A.; Bauduin, P.; Touraud, D.; Kunz, W.; Azemar, N.; Solans,

C. Commun. Present. J. Comite Esp. Deterg. 2004, 34, 273.

(28) Kamenka, N.; El Amrani, M.; Appell, J.; Lindheimer, M. J. Colloid Interface Sci. 1991, 143, 463.

(29) Soederman, O.; Herrington, K. L.; Kaler, E. W.; Miller, D. D. Langmuir

1997, 13,5531 .

(30) O'Connor, A. J.; Hatton, T. A.; Bose, A. Langmuir 1997, 13, 6931.

(31) Filipovič-Vincekovič, N.; Bujan, M.; Smit, I.; Tušek-Božič, L.; Stefanič,

I. J. Colloid Interface Sci. 1998, 201, 59.

(32) Yin, H.; Zhou, Z.; Huang, J.; Zheng, R.; Zhang, Y. Angew. Chem., Int. Ed. 2003, 42, 2188.

(33) Yin, H.; Lei, S.; Zhu, S.; Huang, J.; Ye, J. Chem.-Eur. J. 2006, 12, 2825.

(34) Zhai, L.; Li, G.; Sun, Z. Colloids Surf., A 2001, 190, 275.

(35) Zhai, L.; Zhao, M.; Sun, D.; Hao, J.; Zhang, L. J. Phys. Chem. B 2005, $109,5627$. 271.

(36) Hao, L.; Nan, Y.; Liu, H.; Hu, Y. J. Dispersion Sci. Technol. 2006, 27,

(37) Yuet, P. K.; Blankschtein, D. Langmuir 1996, 12, 3802.

(38) Pashley, R. M.; McGuiggan, P. M.; Ninham, B. W.; Evans, D. F.; Brady, J. J. Phys. Chem. 1986, 90, 1637.

(39) Leontidis, E. Curr. Opin. Colloid Interface Sci. 2002, 7, 81 and refs therein.

(40) Kabalnov, A.; Olsson, U.; Wennerstroem, H. J. Phys. Chem. 1995, 99, 6220.
We are concerned with the influence of salts on a well-studied catanionic system ${ }^{41,42}$ composed of sodium dodecylsulfate (SDS) and dodecyltrimethylammonium bromide (DTAB) in aqueous solution, with an excess of anionic surfactant. Increasing amounts of different salts were successively added to a solution of mixed SDS/DTAB micelles. The micellar system was first characterized by rheometric measurements. The transition from micelles to vesicles was studied using dynamic light scattering (DLS), cryotransmission electron microscopy (cryo-TEM), and freezefracture TEM (FF-TEM). To date, the focus has been mainly on anions because they usually show a stronger Hofmeister effect than cations. ${ }^{39}$ However, in net anionic systems, the transition from micelles to vesicles is mainly sensitive to the type of cation in the added salt. The observed cation specificity was confirmed by changing the sodium counterion of SDS by lithium. Such specific salt effects probably play a significant role in biological systems (e.g., in the formation of vesicles in the postsynaptic environment leading to the encapsulation of the neuro-transmitter or in the polarization/depolarization processes of biological membranes). ${ }^{43-45}$

\section{Experimental Procedures}

Materials. The anionic surfactants, $99 \%$ sodium dodecylsulfate (SDS) and lithium dodecylsulfate (LiDS), were purchased from Merck. The cationic surfactant used was $99 \%$ dodecyltrimethylammonium bromide (DTAB) purchased from Aldrich. All sodium, chloride, and bromide salts used in the experiments were supplied by Merck. All chemicals mentioned previously were used as received without further purification. Millipore water was used as a solvent in all cases.

Sample Preparation. Surfactant stock solutions were prepared by dissolving weighed amounts of dried substances in Millipore water. The solutions were then left for $24 \mathrm{~h}$ to equilibrate at $25^{\circ} \mathrm{C}$. The catanionic solutions were prepared by mixing the surfactant stock solutions to obtain a fixed anionic/cationic surfactant mass ratio of 70:30 (this corresponds to a molar ratio of about 2.5:1). The total surfactant concentration was kept at $1 \mathrm{wt} \%$ at all times. Salts were added to the micellar solution at increasing concentrations. The solutions were then stirred and left to equilibrate for a week at $25{ }^{\circ} \mathrm{C}$ before making measurements.

Turbidity and Dynamic Light Scattering (DLS) Measurements. Turbidity measurements were carried out with a Cary-3E UV-vis spectrophotometer at a wavelength of $414 \mathrm{~nm}$. Particle size analysis was performed using a Zetasizer 3000 PCS (Malvern Instruments Ltd.), equipped with a $5 \mathrm{~mW}$ helium neon laser with a wavelength output of $633 \mathrm{~nm}$. The scattering angle was $90^{\circ}$, and the intensity autocorrelation functions were analyzed using the Contin software. All measurements were performed at $25^{\circ} \mathrm{C}$.

Rheology. Rheological experiments were performed on a Brookfield DV-III + rate controlled rheometer. A cone-and-plate geometry of $48 \mathrm{~mm}$ diameter and with a $0.8^{\circ}$ cone angle was used (spindle model CP-40).

Cryo-Transmission Electron Microscopy (Cryo-TEM). Specimens for cryo-TEM were prepared by placing a small drop (ca. 4 $\mu \mathrm{L}$ ) of the sample on a holey carbon grid. Immediately after blotting with a filter film to obtain a thin liquid film over the grid, the sample was plunged into liquid ethane (at its melting temperature). The vitrified film was then transferred under liquid nitrogen to the electron microscope. The grid was examined with a Zeiss EM922 EF transmission electron microscope (Zeiss NTS GmbH). Examinations were carried out at temperatures around $90 \mathrm{~K}$. The TEM was operated at an acceleration voltage of $200 \mathrm{kV}$. Zero-loss filtered images (DE

(41) Brasher, L. L.; Herrington, K. L.; Kaler, E. W. Langmuir 1995, 11, 4267.

(42) Herrington, K. L.; Kaler, E. W.; Miller, D. D.; Zasadzinski, J. A.; Chiruvolu, S. J. Phys. Chem. 1993, 97, 13792.

(43) Dani, J. A.; Sanchez, J. A.; Hille, B. J. Gen. Physiol. 1983, 81, 255.

(44) Clarke, R. J.; Lüpfert, C. Biophys. J. 1999, 76, 2614.

(45) Sachs, J. N.; Nanda, H.; Petrache, H. I.; Woolf, T. B. Biophys. J. 2004, 86,3772 . 


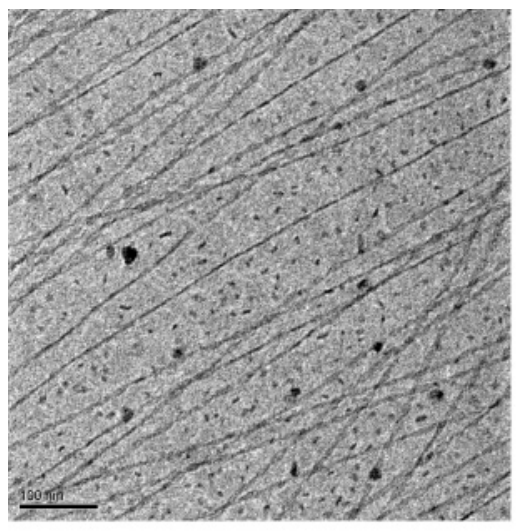

(a)

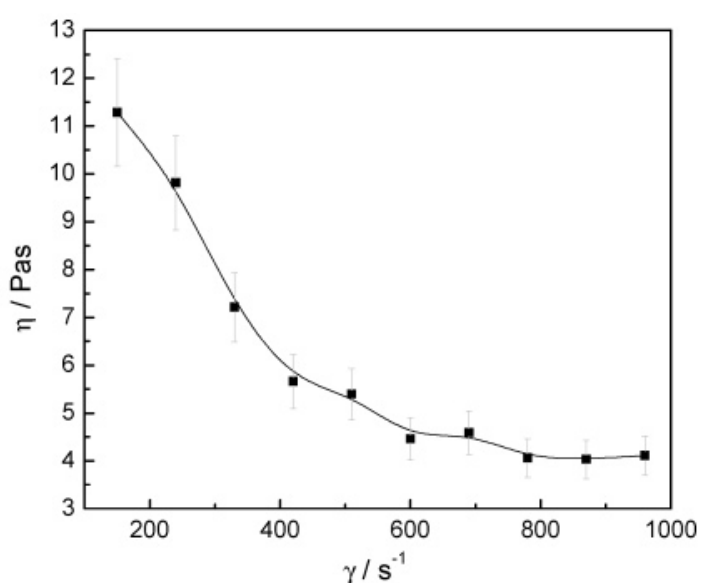

(b)

Figure 1. (a) Cryo-TEM photograph of a SDS/DTAB aqueous solution at a molar ratio of 2.5:1 and a total surfactant concentration of 1 wt \%. The bar in panel a represents $100 \mathrm{~nm}$. (b) Viscosity of the same sample as a function of shear rate.

$=0 \mathrm{eV})$ were taken under reduced dose conditions $(100-1000$ $\mathrm{e} / \mathrm{nm}^{2}$ ). Images were registered digitally by a bottom mounted CCD camera system (Ultrascan 1000, Gatan) combined and processed with a digital imaging processing system (Digital Micrograph 3.9 for GMS 1.4).

Freeze-Fracture Electron Microscopy. Samples used for cryofracture were cryoprotected by $30 \%$ glycerol and frozen in liquid $\mathrm{N}_{2}$. Freeze - fracture was performed in a Balzers apparatus at -150 ${ }^{\circ} \mathrm{C}$ under a vacuum of $10^{-6}$ Torrs. Metallic replicas were obtained by $\mathrm{Pt}$ and carbon shadowing of fracture surfaces. The replicas were examined and photographed with a Philips CM 12 transmission electron microscope.

\section{Results}

Characterization of SDS/DTAB Micellar Solution. The system under study is a well-known mixture of cationic and anionic single chain surfactants. The total surfactant concentration (1 wt \%; $\sim 34 \mathrm{mM}$ ) and the anionic/cationic molar ratio $(2.5: 1)$ remained constant throughout all the experiments. The initial sample was colorless and isotropic, corresponding to the micellar region of the phase diagram. ${ }^{42}$ DLS measurements confirm a micellar solution, indicating a hydrodynamic radius $\left(R_{\mathrm{H}}\right)$ of 10 $\mathrm{nm}$ and a relatively high polydispersity index $(0.27)$. Figure 1a shows a cryo-TEM image of our reference solution (without added salt), exhibiting very long rod- or ribbon-like micelles, in equilibrium with spherical micelles (hence explaining the high polydispersity). Long rod-like micelles have already been observed by SANS measurements in systems similar to ours. ${ }^{46}$ Results from rheometry experiments show that the viscosity decreases with applied shear rate (Figure 1b), therefore exhibiting properties of non-Newtonian shear-thinning fluids. This kind of behavior is common for solutions containing large non-spherical molecules in a solvent with smaller molecules. It is generally supposed that the large molecular chains tumble at random and affect large volumes of fluid under low shear but that they gradually align themselves in the direction of increasing shear and produce less resistance. This behavior confirms the presence of rod-like micelles. No enthalpy change could be detected by differential scanning calorimetry so that no information could be deduced about possible phase transitions occurring in the system between 10 and $80{ }^{\circ} \mathrm{C} .{ }^{47-49}$ Probably, the amount of surfactant was too low for such a detection with our equipment.

(46) Bergström, M.; Pedersen, J. S. Langmuir 1999, 15, 2250.

(47) Vautrin, C.; Dubois, M.; Zemb, T.; Schmölzer, S.; Hoffman, H.; Gradzielski, M. Colloids Surf., A 2003, 217, 165.

(48) Marques, E. F.; Khan, A.; Lindman, B. Thermochim. Acta 2002, 394, 31.

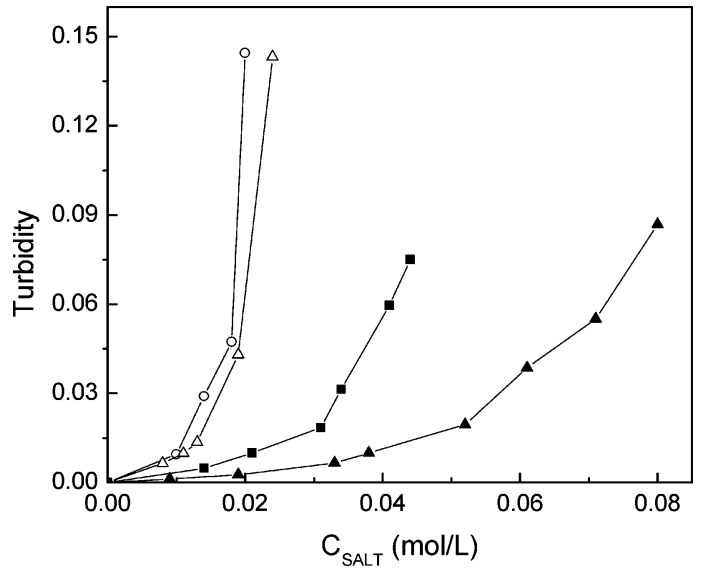

Figure 2. Increase of the turbidity of SDS/DTAB solutions upon addition of chloride salts: $\mathrm{CsCl}(\mathrm{O}), \mathrm{KCl}(\triangle), \mathrm{NaCl}(\mathbf{\square})$, and $\mathrm{LiCl}$ $(\mathbf{\Lambda})$.

Counterion Effects. The effect of various cations was studied by varying the concentration of different alkali chloride salts ( $\mathrm{LiCl}, \mathrm{NaCl}, \mathrm{KCl}, \mathrm{RbCl}$, and $\mathrm{CsCl}$ ). As the concentration of salt in the system was increased, the solutions exhibited a transition from a colorless to a blue solution, the blue color being typical of the presence of large objects. This transition could be observed for all salts; however, the concentration at which vesicles appeared is strongly dependent on the nature of the cation. A further increase of added salt concentration finally led to a phase separation, with one of the two phases being blue and isotropic and the other turbid.

Samples with different salt concentrations were analyzed by dynamic light scattering. The addition of chloride salts causes an increase in average particle size and a certain turbidity of the solution (Figure 2). DLS indicated a significant increase in the mean hydrodynamic radius $\left(R_{\mathrm{H}}\right)$ of the micelles from 10 to ca. $70 \mathrm{~nm}$ (Figure $3 \mathrm{a}$ ). In agreement with our visual observations, the rate of increase of the measured hydrodynamic radius was different for each chloride salt. This highlights a strong cation specificity. For instance, a small amount of $\mathrm{CsCl}$ or $\mathrm{RbCl}(<20$ $\mathrm{mM}$ ) was sufficient to dramatically increase the hydrodynamic radius (to $70 \mathrm{~nm}$ ), whereas with $\mathrm{LiCl}$, concentrations higher than $60 \mathrm{mM}$ were needed to obtain particles of that size. A classification

(49) Tsuchiya, K.; Nakanishi, H.; Sakai, H.; Abe, M. Langmuir 2004, 20, 


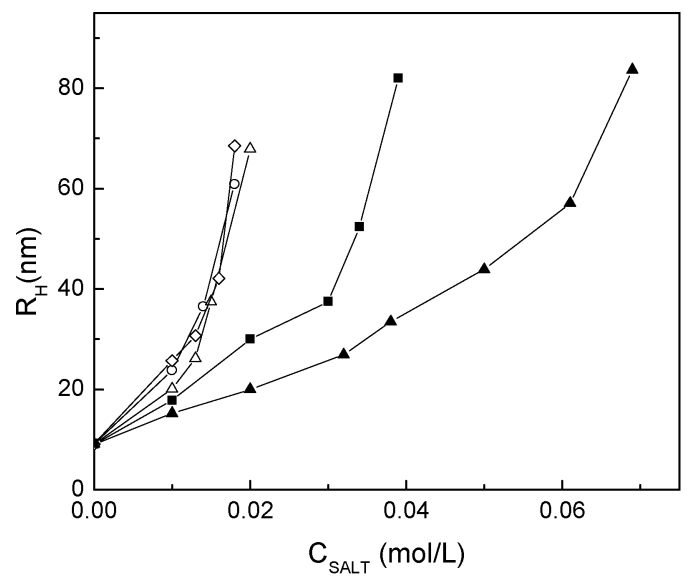

(a)

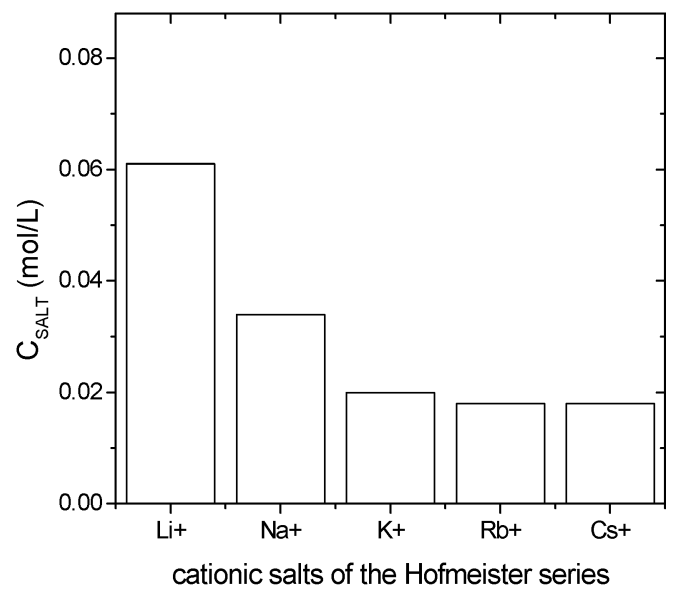

(b)

Figure 3. (a) Effect of chloride salts on the growth of the hydrodynamic radii $R_{\mathrm{H}}$ of the catanionic aggregates: $\mathrm{CsCl}(\mathrm{O}), \mathrm{RbCl}(\diamond), \mathrm{KCl}$ $(\triangle), \mathrm{NaCl}(\mathbf{\square})$, and $\mathrm{LiCl}(\mathbf{\Delta})$. (b) Amount of chloride salt (mol/L) necessary to increase the size of the aggregates to $50 \mathrm{~nm}$.

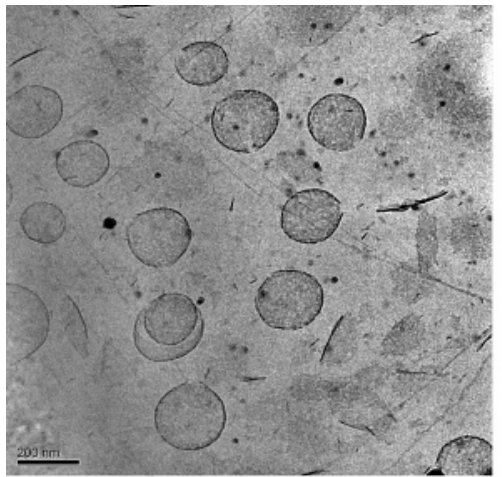

(a)

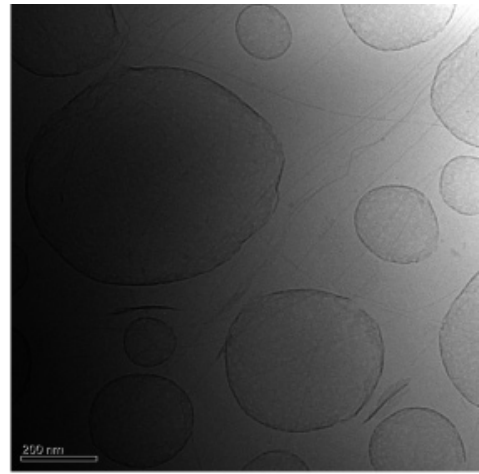

(b)

Figure 4. Cryo-TEM photographs of a SDS/DTAB aqueous solution at a molar ratio of 2.5:1 and a total surfactant concentration of 1 wt $\%$ with (a) $44 \mathrm{mM} \mathrm{NaCl}$ and (b) $19 \mathrm{mM} \mathrm{CsCl}$. The bar represents $200 \mathrm{~nm}$.

of the cations can be made according to their ability to increase the measured hydrodynamic radius of the aggregates

$$
\mathrm{Cs}^{+} \sim \mathrm{Rb}^{+} \gtrsim \mathrm{K}^{+}>\mathrm{Na}^{+}>\mathrm{Li}^{+}
$$

The same ordering of the cations can be established when the index of polydispersity (Figure S1, Supporting Information) and the turbidity (Figure 2) are plotted against the concentration of added salt.

To characterize the observed specific cation effect, the amount of each salt necessary to obtain a measured hydrodynamic radius of $50 \mathrm{~nm}$ was plotted as a function of the type of cation, ordered according to the classical Hofmeister series ${ }^{50}$ (Figure 3b).

Some samples were analyzed by cryo-TEM to determine the type of aggregates present in the solutions. Images of samples containing different amounts of salt confirm the increase in the particle size. The addition of $44 \mathrm{mM}$ sodium chloride (Figure 4a) produces large aggregates, which appear to be vesicles in equilibrium with ribbon-like micelles. The size of the diameter measured by DLS is in rough agreement with the size of most vesicles present on the photographs (ca. $200 \mathrm{~nm}$ ). As can be observed in Figure 4b, the addition of cesium chloride at lower concentrations $(19 \mathrm{mM})$ also results in the formation of vesicles. The average size of the aggregates in this case is hard to determine because of the very high polydispersity of the solution. The vesicles, whose diameters range from 100 to $500 \mathrm{~nm}$, are in

(50) Bauduin, P.; Renoncourt, A.; Touraud, D.; Kunz, W.; Ninham, B. W. Curr. Opin. Colloid Interface Sci. 2004, 9, 43. equilibrium with ribbon-like micelles. The increase in measured $R_{\mathrm{H}}$ is most likely due to the combined effects: formation of vesicles as well as the elongation of rods. The latter effect is well-known in the literature. ${ }^{51,52}$

Samples with $30 \mathrm{mM} \mathrm{LiCl}$ and $\mathrm{NaCl}$ were further analyzed using freeze-fracture microscopy. FF-TEM is useful because of the advantageous fracture course within hydrophobic zones. This yields a more precise insight into vesicle structure. The presence of vesicles, already determined by cryo-TEM, was confirmed. FF-TEM shows the existence of unilamellar vesicles with the average sizes ranging from 50 to $70 \mathrm{~nm}$ (Figure 5a,b) and also of discs. The vesicles also appear to be polyhedral. Faceted vesicles are most likely due to the fact that the tails of the surfactants are rather stiff due to crystallization. This is commonly seen in catanionic systems.

Thus, both cryo- and FF-TEM photographs confirm the transition from micellar (ribbon-like) systems to vesicles through salt addition. The discrepancy in size is most likely due to the technique used; the size of the object is dependent on the area where the samples were fractured.

The binding of counterions in mixed catanionic micelle/solution interfaces depends on the surfactant molar ratio ${ }^{53}$ (i.e., the charge of the aggregates). Preliminary zeta potential measurements of the catanionic solutions with and without salt confirm the presence of negatively charged aggregates (unpublished results). Therefore,

(51) Ikeda, S.; Hayashi, S.; Imae, T. J. Phys. Chem. 1981, 85, 106.

(52) Gamboa, C., Sepulveda, L. J. Colloid Interface Sci. 1986, 113, 566.

(53) Filipovič-Vincekovič, N.; Škrtič, D. Colloid Polym. Sci. 1988, 266, 954. 


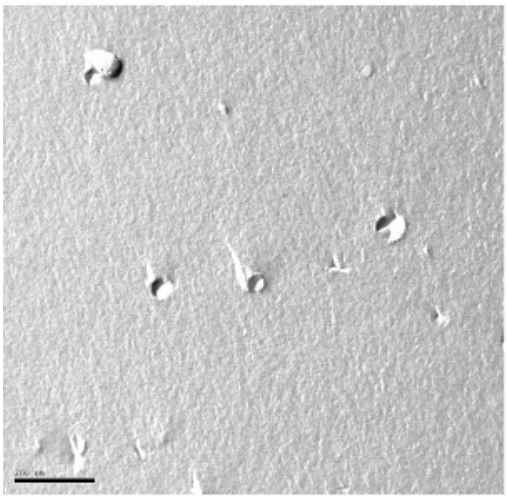

(a)

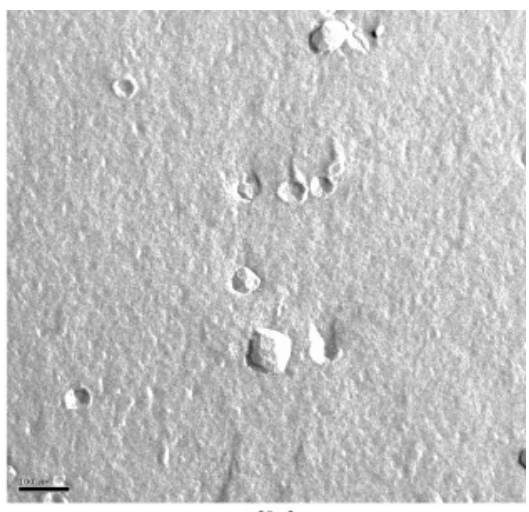

(b)

Figure 5. FF-TEM photograph representing the effect of (a) $30 \mathrm{mM} \mathrm{NaCl}$ and (b) $30 \mathrm{mM} \mathrm{LiCl}$ on the reference SDS/DTAB micellar solution. The bar represents $200 \mathrm{~nm}$ in panel a and $100 \mathrm{~nm}$ in panel b. The molarity in the case of FF-TEM experiments corresponds to the concentration of the solutions prior to cryo-protecting.

no anion specificity was to be expected. Samples were nevertheless checked also in the presence of various sodium salts $(\mathrm{NaCl}$, $\mathrm{NaBr}, \mathrm{NaI}, \mathrm{NaOH}, \mathrm{NaClO}_{4}, \mathrm{NaSCN}$, and $\mathrm{NaOAc}$ ). All salts proved to have a significant influence on the growth of the micelles; however, no significant specificity could be found for the different anions (Figure S2, Supporting Information).

To observe the influence of the anion of the added salt on the observed cation specificity, we added bromide salts with the same series of cations as stated previously. From visual observations and DLS measurements, a similar cation specificity as with chloride salts was found. Further experiments were performed by adding hydroxide and acetate salts instead of chloride or bromide. The results with these salts lead to similar observations and are therefore not presented. From these results, one can conclude that there is no influence of the anion nature of the added salt on the cation specificity.

Two non-ionic additives, glucose and urea, having, respectively, salting-out and salting-in effects, were also added to the same mixed micelle solutions. No effect whatsoever on the growth of the measured hydrodynamic radius could be noticed. Even though glucose and urea were added at a concentration as high as $1 \mathrm{~mol} / \mathrm{L}$, no increase in the hydrodynamic radius of the aggregates was found.

The cation specificity was studied on another catanionic system with the same cationic surfactant (DTAB) but with lithium dodecylsulfate LiDS as the anionic surfactant. The two surfactants were mixed at the same anionic/cationic mass ratio of 70:30, at a total surfactant concentration of $1 \mathrm{wt} \%$. The solution was colorless and isotropic. Results from DLS measurements confirm a micellar solution $\left(R_{\mathrm{H}}=7.42 \mathrm{~nm}\right.$; polydispersity index $\left.=0.2\right)$. Three different chloride salts were added to the system: $\mathrm{LiCl}$, $\mathrm{NaCl}$, and $\mathrm{CsCl}$.. Once again, an increase in the size of the particles was observed upon the addition of salt. The order of the Hofmeister series for these four salts appears to be the same as the classification established before when the salts were added to the SDS/DTAB system

$$
\mathrm{Cs}^{+}>\mathrm{Na}^{+}>\mathrm{Li}^{+}
$$

To check whether the presence of atmospheric $\mathrm{CO}_{2}$ played any role on the existence of vesicles, a sample containing $40 \mathrm{mM}$ $\mathrm{NaCl}$ was degassed for $24 \mathrm{~h}$. The blue color remained, indicating that vesicles were still present.

\section{Discussion}

Aggregation Behavior of Catanionic Systems. The main thermodynamic driving force for the association of a cationic and an anionic surfactant mixture is the release of counterions from the aggregate surfaces. This results in a large entropy increase. For these systems, a non-monotonic change in $P$ is observed, with a pronounced maximum as the mixing ratio is varied. ${ }^{54,55}$ In the system presented here, vesicles could only be formed when the anionic surfactant was in molar excess as compared to the cationic surfactant. Therefore, only this ratio is considered here. The packing parameter at salinity zero was smaller than the one obtained after salt was added to the system. Therefore, solutions without salt exhibit micelles (spherical and rod-like). As salt is added, the headgroup is dehydrated, and electrostatic interactions are screened. This causes a decrease in the value of $a$ and consequently an increase of the structural packing parameter. The cost of free energy to make a vesicle is now less than the cost to form a rod.

Counterion Properties. The effect of salts on a charged system can differ much depending on the salting-in or salting-out properties of their ions. ${ }^{56-58}$ Salting-out ions are usually small, with relatively small polarizabilities. They have high electric fields at short distances and have tightly bound hydration water. NMR evidence ${ }^{39}$ suggests that small ions do not show specific binding to micelles and retain their mobility and their water of hydration right up to the micellar surface, ${ }^{59}$ although this result depends on the type of surfactants and is mainly valid for alkylsulfates. ${ }^{60}$ Salting-in ions are usually large, with significant polarizabilities. They have weak electric fields and a loose hydration sheath, which can be easily removed. NMR proves that they perturb phospholipid (surfactant) headgroups in a significant way, probably through ion pairing. ${ }^{60}$ Each salt is therefore expected to have an individual influence on vesicle formation, whether it tends to adsorb at the interface between micelle and water or remains strongly hydrated in the solution.

Anionic Effect. The addition of sodium salts proved to have a significant effect on the growth of the micelles (Figure S2). This increase of particle size is mainly due to a decrease of the headgroup repulsions because of electrostatic screening. Since the micelles are very probably negatively charged, the anions will not come into close contact with the micellar surfaces, and

(54) Evans, D. F.; Wennerström, H. The Colloidal Domain, 2nd ed.; WileyVCH: Weinheim, 1999

(55) Holmberg, K.; Jönsson, B.; Kronberg, B.; Lindman, B. Surfactants and Polymers in Aqueous Solutions, 2nd ed.; John Wiley \& Sons: New York, 2003.

(56) Kunz, W.; Lo Nostro, P.; Ninham, B. W. Curr. Opin. Colloid Interface Sci. 2004, 9, 1 .

(57) Vrbka, L.; Jungwirth, P.; Bauduin, P.; Touraud, D.; Kunz, W. J. Phys. Chem. B 2006, 110, 7036 .

(58) Collins, K. D.; Washabaugh, M. W. Q. Rev. Biophys. 1985, 18, 323.

(59) Gustavsson, H.; Lindman, B. J. Am. Chem. Soc. 1978, 100, 4647.

(60) Hedin, N.; Furo, I.; Eriksson, P. O. J. Phys. Chem. B 2000, 140, 8544. 
the onset of vesicle formation occurs at approximately the same concentration for all sodium salts. The small differences in radius size observed (Figure S2) are likely to be due to the differences in the hydration of the anions; in the case of strongly hydrated $\mathrm{Cl}^{-}$, larger vesicles were observed than in the presence of other less hydrated ions. A similar effect was previously observed in studies of negatively charged phospholipid vesicles. ${ }^{61}$

Alkali Cation Effect on the Micelle-to-Vesicle Transition. Collins $^{62}$ proposed an interesting concept of matching water affinities. Briefly, he concluded from various experimental results that small cosmotropic ions can come close together, forming inner sphere ion pairs without intermediate water molecules. The same is supposed to be true for large chaotropic ions, whereas when a cosmotropic ion approaches a chaotropic counterion, the ions should remain separated by at least one water molecule. Although this concept might be oversimplified, as far as the strict distinction between direct and solvent separated ion pairs is concerned, it provides us with a simple model of specific ion-ion interactions.

In the present case, the headgroups in excess are alkylsulfates. In contrast to doubly charged sulfate ions, such headgroups have a more chaotropic behavior. With this assumption and according to Collins' concept, alkylsulfates should come in close contact with chaotropic ions like cesium, whereas lithium ions remain further away. Therefore, it is expected that $\mathrm{Cs}^{+}$screen the negative charge excess on the aggregates more efficiently than $\mathrm{Li}^{+}$, and this is precisely what is observed, cf. Figure 3a,b. The same ordering of cations was found in systems containing pure SDS micelles ${ }^{63}$ and in the case of another anionic surfactant with a sulfate group, sodium dodecylbenzenesulfonate. ${ }^{64}$

To make a more quantitative analysis, we compared the salt concentrations to the excess concentration of SDS (as compared to DTAB), which is approximately $0.015 \mathrm{~mol} / \mathrm{L}$. From Figure 3 , it can be inferred that this concentration roughly corresponds to the asymptotic limit for micelle-to-vesicle transitions in the case of $\mathrm{K}^{+}, \mathrm{Rb}^{+}$, and $\mathrm{Cs}^{+}$chlorides. Therefore, it may be concluded that these cations have a strong propensity to the sulfate groups and that sulfate headgroup-cation pairs are formed; in this case, the excess negative charge of the vesicles is neutralized. This finding is in agreement with the association constants found for a similar surfactant $n$-octylbenzenesulfonate. ${ }^{65}$

It is worth coming back to the specific role of the surfactant headgroup. While in the case of alkylsulfates the previously mentioned series is found, different results are observed in the case of phospholipids. Experiments performed on the negatively charged phospholipid dioleoylphosphatidylglycerol (DOPG) show that the maximum in $R_{\mathrm{H}}$ is found for $\mathrm{K}^{+} .66$ According to Collins' concept, it is as if the negatively charged phosphate group behaves like an intermediate case somewhere between a cosmotropic and a chaotropic object. Perhaps this behavior is due to the combined effects of hydration and specific (site) binding to the DOPG group. Similar studies were also performed on vesicles composed of the zwitterionic phospholipids phosphatidylcholine. The additions of various cations again had an effect on the vesicles; however, the effects were significantly smaller that those observed by varying the anion. ${ }^{44}$

(61) Claessens, M. M. A. E.; van Oort, B. F.; Leermakers, F. A. M.; Hoekstra, F. A.; Cohen Stuart, M. A. Biophys. J. 2004, 87, 3882.

(62) Collins, K. D. Methods 2004, 34, 300.

(63) Haverd, V. E.; Warr, G. G. Langmuir 2000, 16, 157 and refs therein.

(64) Sein, A.; Engberts, J. B. F. N. Langmuir 1995, 11, 455.

(65) Kamenka, N.; Lindman, B.; Fontell, K.; Chorro, M.; Brun, B. C. R. Acad. Sci. 1977, 284, 403.

(66) Claessens, M. M. A. E. Size Regulation and Stability of Charged Lipid Vesicles. Ph.D. Thesis, Wageningen University, 2003.

(67) Demarcq, H. Ind. Corps Gras 1946, 2, 341.
Finally, there is much evidence that alkyl carboxylates show exactly the inverse cation specificity as compared to alkylsulfates, thus behaving more like a cosmotrope. ${ }^{59,63,67,68}$ - For the moment, it is not clear why these different headgroups behave so differently toward cations, maybe because carboxylates show a significant complexing behavior toward cations. Detailed computer simulations $^{57}$ would help to shed some light on this mystery.

Non-ionic Effects. The fact that the addition of glucose and urea had no effect on the growth of the micelles (no micelleto-vesicle transition was observed) suggests that electrostatic interaction is necessary and that this is the first-order effect. The reasons are the following.

The hydration numbers of $\mathrm{Cs}^{+}$and glucose are $4.3^{69}$ and 3.5, ${ }^{70}$ respectively, and so are quite similar. Nevertheless, even high concentrations of glucose and urea (up to $1 \mathrm{M}$ ) had no effect on the growth of the surfactant aggregates. This confirms that dehydration of the headgroups alone is not sufficient to trigger the micelle-to-vesicle transition. The reason must be sought in the electrostatics. Even if these uncharged molecules modified the surrounding water structure, this effect is not strong enough to significantly change the curvature via adsorption to the headgroups.

If the micelles consisted of just one type of charged surfactant, then the addition of salt would screen the repulsion between the headgroups, causing the surfactant molecules to arrange in a bilayer. The opposite case would be if the cationic and anionic surfactants were present in equimolar amounts in the micelles. Then, the salts would screen the attraction between them, most likely causing the distance between the headgroups to increase. Since we assume that in our case the mixed micelles contain an excess of the anionic surfactant, there must be an asymmetric distribution of charges (the same idea is proposed in a following paper ${ }^{68}$ ). Therefore, the addition of salt should have a similar, although somewhat attenuated, effect as in the case of micelles formed only by anionic surfactants.

\section{Conclusion}

Through the addition of salts, a transition from rod-like micelles vesicles was observed in aqueous solutions composed of DTAB and an excess of SDS. Whereas no anion specificity for the added salts appeared in the formation of vesicles, the nature of the cation was found to influence strongly the critical salt concentrations, in which micelles turn to vesicles. In the present case of negatively charged vesicles, ion specific effects were expected for cations since they accumulate in high concentrations in the vicinity of the vesicle. The observed cation specificity followed the classical series for cation adsorption to sulfate headgroups. The ion specificity could be qualitatively explained according to Collins' concept of matching water affinities. To this purpose, the headgroup of an alkylsulfate had to be regarded as a chaotrope.

Supporting Information Available: Polydispersity index of SDS/DTAB solutions upon addition of chloride salts and increase in size of catanionic aggregates after the addition of sodium salts. This material is available free of charge via the Internet at http://pubs.acs.org.

LA062837Z

(68) Results from our laboratory. Publications in preparation.

(69) Marcus, Y. Ion Solvation; John Wiley \& Sons: New York, 1985; p 100.

(70) Beenackers, J. A. W. M.; Kuster, B. F. M.; van der Baan, H. S. Carbohydr. Res. 1985, 140, 169. 